\title{
Multiple Ways for Stress Sensing and Regulation of the Endoplasmic Reticulum-stress Sensors
}

\author{
Quynh Giang Le ${ }^{1,2}$ and Yukio Kimata ${ }^{3^{*}}$ \\ ${ }^{1}$ Institute of Biomedicine and Pharmacy, Vietnam Military Medical University, 222 Phung Hung, Ha Dong, \\ Ha Noi, Vietnam, ${ }^{2}$ Institute of Biotechnology, Vietnam Academy of Science and Technology, 18 Hoang Quoc \\ Viet road, Cau Giay, Ha Noi, Vietnam, ${ }^{3}$ Graduate School of Science and Technology, Nara Institute of \\ Science and Technology, 8916-5 Takayama, Ikoma, Nara, 630-0192, Japan
}

\begin{abstract}
Dysfunction of the endoplasmic reticulum (ER), so-called ER stress, is accompanied with accumulation of unfolded proteins in the ER. Eukaryotic cells commonly have an ER-located transmembrane protein, Ire1, which triggers cellular protective events against ER stress. In animal cells, PERK and ATF6 also initiate the ER-stress response. As a common strategy to control the activity of these ER-stress sensors, an ERresident molecular chaperone, $\mathrm{BiP}$, serves as their negative regulator, and dissociates from them in response to ER stress. Although it sounds reasonable that unfolded proteins and Ire1 compete for BiP association, some publications argue against this competition model. Moreover, yeast Ire1 (and possibly also the mammalian major Ire1 paralogue IRE1 $\alpha$ ) directly detects ER-accumulated unfolded proteins, and subsequently oligomerizes for its further activation. Apart from protein misfolding, the saturation of membrane phospholipids is another outcome of ER-stressing stimuli, which is sensed by the transmembrane domain of Ire1. This review describes the canonical and up-to-date insights concerning stress-sensing and regulatory mechanisms of yeast Ire1 and metazoan ER-stress sensors.
\end{abstract}

Key words: endoplasmic reticulum, stress, unfolded protein response, molecular chaperone

\section{Introduction}

The endoplasmic reticulum (ER) is a membrane-bound organelle in which most of the secretory and transmembrane proteins are folded and assembled in eukaryotic cells. Once properly matured in the ER, proteins are packed into transport vesicles and carried to the cell surface or other organelles via the Golgi apparatus. Dysfunction of the ER

*To whom correspondence should be addressed: Yukio Kimata, Graduate School of Science and Technology, Nara Institute of Science and Technology, 8916-5 Takayama, Ikoma, Nara, 630-0192, Japan.

E-mail: kimata@bs.naist.jp

Abbreviations: AH, amphipathic helix; ATF, activating transcription factor; ATF6(C), C-terminal fragment of ATF6; ATF6(N), N-terminal fragment of ATF6; CHOP, C/EBP homologous protein; cLD, core luminal domain; COPII, coat protein complex II; CSSR, core stress-sensing region; DTT, dithiothreitol; eIF2 $\alpha, \alpha$ subunit the eukaryotic initiation factor 2; ER, endoplasmic reticulum; HACli, induced $\mathrm{HACl}$; HAClu, uninduced $H A C 1$; HSP, heat shock protein; JIDR, juxtamembrane intrinsically disordered region; JNK, c-Jun N-terminal kinase; LBS, lipid bilayer stress; NBD, nucleotide-binding domain; NBP, nucleotide-binding pocket NUCR, N-terminal unconserved region; PERK, PKR-like endoplasmic reticulum kinase; PC, phosphatidyl choline; RNase, (endo)ribonuclease; RIDD, regulated Ire1-dependent decay; SBD, substrate-binding domain; $\mathrm{TMH}$, transmembrane helix; UPR, unfolded protein response; VLCFA, very-long-chain fatty acid; XBP1, X-box binding protein 1; XBP1s, spliced XBP1; XBP1u, unspliced XBP1. is thus associated with accumulation of unfolded proteins in the ER, and is now collectively called ER stress. Kozutsumi et al. (1988) reported that, in mammalian cells, ER stress results in transcriptional induction of some ERlocated proteins including BiP, which is a molecular chaperone belonging to the heat shock protein 70 (HSP70) family (Behnke et al., 2015). This cellular response is conserved throughout eukaryotic species, and is known as the ER stress response or the unfolded protein response (UPR).

The intracellular signaling pathway of the UPR has been initially uncovered through genetic studies using Saccharomyces cerevisiae (hereafter simply called yeast) as a model organism. As illustrated in Fig. 1, an ER-located type-I transmembrane protein Ire1 carries two enzymatic motifs as an endoribonuclease (RNase) and a Ser/Thr protein kinase, and triggers the UPR (Cox et al., 1993; Mori et al., 1993; Shamu and Walter, 1996; Sidrauski and Walter, 1997). At least in yeast cells, it appears unlikely that Ire1 phosphorylates another protein(s). Upon ER stress, yeast Ire1 is trans-autophosphorylated, which means that one Ire1 molecule phosphorylates another self-associated Ire1 molecule (Shamu and Walter, 1996). Yeast Ire1 is then activated as an RNase to promote $H A C 1$-mRNA splicing for conversion of the precursor $H A C l \mathrm{u}$ form to the mature 
Yeast Ire1

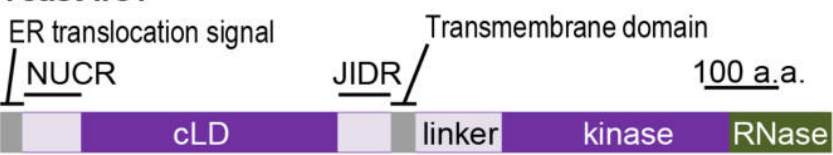

IRE1 $\alpha$ (human)

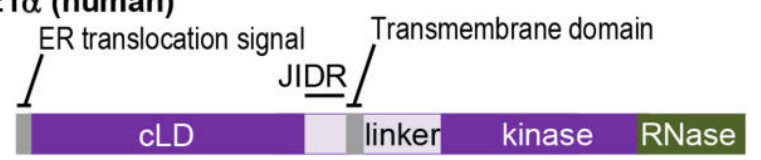

PERK (human)

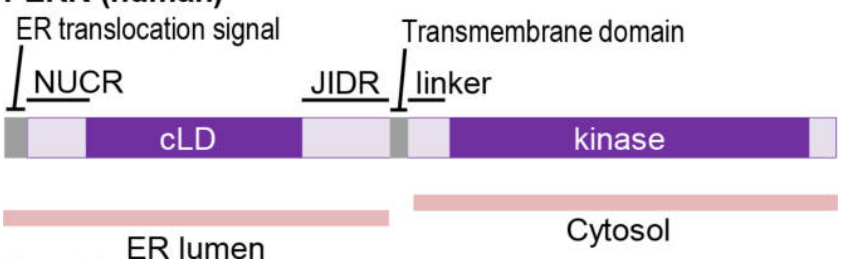

Fig. 1. Structure of Ire1 and PERK. Unlike those of the NUCR or the JIDR, the amino-acid sequences of the cLD are weakly but significantly conserved among these proteins. In our previous publication (Kimata et al., 2004), the NUCR, the cLD and the JIDR of the yeast Ire1 were named as Subregions I, II-IV and V.

HACli form (Fig. 2; Cox and Walter, 1996; "u" and "i" respectively stand for "uninduced" and "induced"). The HACli mRNA is then translated into a transcription factor protein that induces various genes including that encoding BiP.
Ire1 is conserved throughout eukaryotic species. Metazoan Ire1 orthologues including the major vertebrate Ire1 paralogue, namely IRE1 $\alpha$ (Fig. 1), promote the splicing of X-box binding protein 1 (XBP1) mRNA (XBP1u; " $u$ " stands for "unspliced"), the mature form of which (XBP1s; "s" stands for "spliced"), as well as that of the yeast HAC1 mRNA, is translated into a transcription factor (Fig. 2; Yoshida et al., 2001; Calfon et al., 2002). Meanwhile, unlike yeast Ire1, metazoan Ire1 orthologues degrade mRNAs encoding proteins that traverse the ER (Fig. 2; Hollien and Weissman, 2006; Maurel et al., 2014). This phenomenon is known as the regulated Ire1-dependent decay (RIDD), and is thought to attenuate protein load into the ER upon ER stress. Vertebrate cells also carry a minor Ire1 paralogue named as IRE1 $\beta$, which, in mouse body, is expressed only in mucin-secreting cells (Tsuru et al., 2013). Ishikawa et al. (2017) reported that IRE1 $\beta$ performs XBP1mRNA splicing, whereas other publications suggested that this is not the main role of IRE1 $\beta$ (Tsuru et al., 2013; Grey et al., 2020). It is also likely that these IRE1 paralogues activate c-Jun N-terminal kinases (JNKs) independently of their RNase activity (Urano et al., 2000).

In vertebrate cells, another ER-located transmembrane protein, the activating transcription factor (ATF) 6, also serves as an ER-stress sensor. Upon ER stress, ATF6 is transported from the ER to the Golgi apparatus, in which ATF6 is cleaved and becomes a soluble and active transcription factor ATF6(N) ("N" stands for "N-terminal"; Haze et al., 1999; Yoshida et al., 2000; Ye et al., 2000; Chen et al., 2002). XBP1s and ATF6 transcriptionally

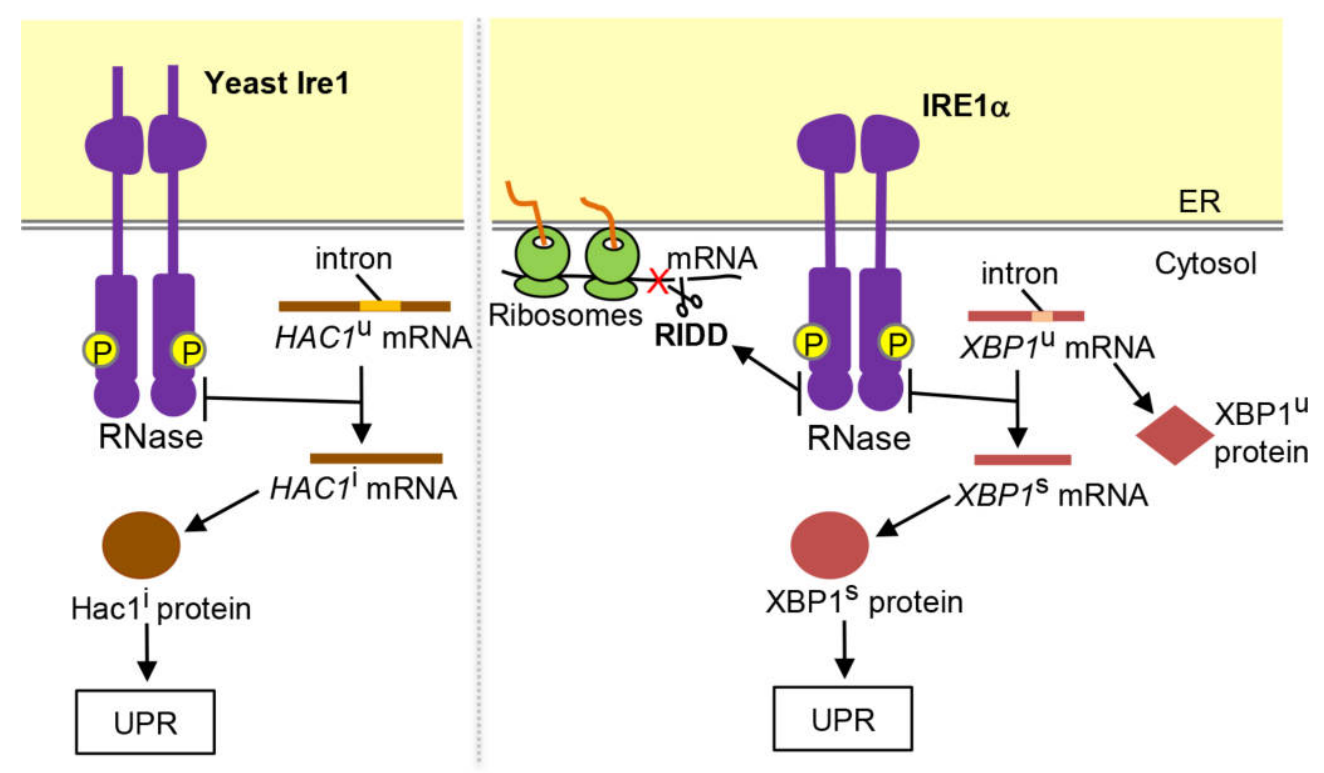

Fig. 2. Functions of yeast Ire1 and mammalian IRE1 $\alpha$. Self-association and auto-phosphorylation of Ire1 lead to its activation as RNase, which evokes the indicated events. While, as described later in this article, Ire1 is more strongly activated as high-order oligomers, here it is presented as dimers. Although not shown in this figure, it is also likely that IRE1 $\alpha$ phosphorylates other proteins. 
induce partly overlapping genes, many of which encode proteins working for the ER (Shoulders et al., 2013). In addition, the XBP1 gene is transcriptionally induced by ATF6 (Yoshida et al., 2001).

Metazoan cells carry another ER-located transmembrane kinase, PKR-like endoplasmic reticulum kinase (PERK), the luminal-domain sequence of which exhibits a weak but significant homology with that of the aforementioned Ire1 orthologues and paralogues (Fig. 1; Harding et al., 1999; Liu et al., 2000). Under ER-stressing conditions, PERK phosphorylates and inactivates the $\alpha$ subunit of the eukaryotic initiation factor 2 (eIF2 $\alpha$ ). While this leads to a global decrement of protein synthesis, which can alleviate ER stress, it is also known that PERK evokes more sophisticated and complicated cellular events (Rozpedek et al., 2016). The phosphorylation of eIF $2 \alpha$ facilitates translation of ATF4 mRNA by skipping its upstream open reading frame, resulting in the initiation of a gene expression program named as the integrated stress response (Harding et al., 2000; Donnelly et al., 2013). The C/EBP homologous protein (CHOP), which contributes to ER stress-induced apoptosis, is one of the downstream induction targets of ATF4 (Zinszner et al., 1998; Harding et al., 2000).

How is ER stress sensed by Ire1 orthologues and PERK? Studies on yeast Ire1 initially provided various intriguing insights to answer this question. Meanwhile, recent biochemical approaches using recombinant IRE1 $\alpha$ and PERK fragments have provided new views, which are sometimes controversial. This review discusses canonical and current understanding of the molecular mechanisms by which they sense ER stress and are regulated. Furthermore, the ER stress-sensing and regulation mechanisms of ATF6 are also described.

\section{Stress-sensing and regulatory mechanism of yeast Ire1}

Since Ire1 is an ER-located transmembrane protein, it is widely believed that its luminal moiety is responsible for controlling Ire1's activity in response to ER conditions. Several experimental data and a computer prediction cumulatively indicate that the luminal moiety of yeast Ire1 has two loosely folded segments (Kimata et al., 2004; Oikawa et al., 2005; Credle et al., 2005; Mathuranyanon et al., 2015), namely the N-terminal unconserved region (NUCR; Fig. 1) and the juxtamembrane intrinsically disordered region (JIDR; Fig. 1). Meanwhile, the central segment of the luminal domain, which is called the core stress-sensing region (CSSR) or the core luminal domain (cLD; Fig. 1), is tightly folded and responsible for the self-association of Ire1 (Credle et al., 2005; Kimata et al., 2007).

Okamura et al. (2000) showed that BiP is associated with yeast Ire1 under normal conditions and dissociates from it in response to ER stress. Moreover, yeast cells only weakly induced the UPR even under ER-stress conditions when carrying $\mathrm{BiP}$ mutations that stabilize the $\mathrm{BiP}-$ Irel association (Kimata et al., 2003). These observations suggest a role of $\mathrm{BiP}$ as a negative regulator of Ire1. Based on deletion mutation analyses, we and others have proposed that the BiP-binding site is located on the JIDR of yeast Ire1 (Kimata et al., 2004; Pincus et al., 2010). Supposing that Ire1 is captured by BiP as a chaperone substrate, it seems reasonable that the BiP-binding site is intrinsically disordered. Albeit less tightly than the wild type, yeast Ire1 mutants not carrying the JIDR are regulated depending on ER stress (Kimata et al., 2004; Pincus et al., 2010). Therefore, it is unlikely that $\mathrm{BiP}$ is the sole master regulator of yeast Ire1.

The NUCR also contributes to suppression of the activity of yeast Ire1 in non-stressed cells (Oikawa et al., 2007; Mathuranyanon et al., 2015). Nevertheless, it is unlikely that BiP binds to the NUCR (Kimata et al., 2004; Oikawa et al., 2007). According to Mathuranyanon et al. (2015), the NUCR intramolecularly interacts with the cLD, inhibiting the cLD-dependent self-association of Ire1 under normal conditions. A yeast Ire1 mutant carrying neither the JIDR nor the NUCR, which here we call $\triangle$ NUCR/ $\triangle$ JIDR Ire1, was self-associated probably as a dimer even under normal conditions (Oikawa et al., 2007; Mathuranyanon et $a l ., 2015)$. This observation suggested that the BiP dissociation from Ire1 contributes to, although not sufficient for, the dimerization of Ire1 under ER-stress conditions (Fig. 3). Since $\Delta$ NUCR/ $\triangle$ JIDR Ire1 was constitutively autophosphorylated in yeast cells, we deduce that Ire1 is automatically auto-phosphorylated when dimerized (Fig. 3; Le et al., 2021).

When yeast cells are strongly ER-stressed, Ire1 exhibits a punctate-like distribution (Kimata et al., 2007; Aragón et al., 2009; Ishiwata-Kimata, 2013b). Since this ER stressdependent localization change, namely the cluster formation of Ire1, was observable even when Ire1 carries the $\Delta$ NUCR/AJIDR mutation (Mathuranyanon et al., 2015), we think that neither the NUCR nor the JIDR is involved in the regulation of this process. Meanwhile, the Ire1 cluster formation is likely based on the properties of the cLD. According to X-ray crystallographic analysis (Credle et al., 2005), the cLD dimer of yeast Ire1 forms a groove-like structure that resembles that of the peptide-binding groove of the major histocompatibility complex I. Further studies by us and others indicated that the cLD actually captures unfolded proteins, leading to its high-order oligomerization (Fig. 3; Kimata et al., 2007; Gardner and Walter, 2011; Promlek et al., 2011). According to Korennykh et al. (2009), clustered Irel molecules exert a stronger RNase activity than Ire1 dimers. Moreover, $H A C l$ mRNA is actively gathered at the Ire1 foci in yeast cells (Aragón et al., 2009; van Anken et al., 2014). It is therefore likely that the Irel cluster formation leads to the efficient splicing of HAC1 mRNA. 


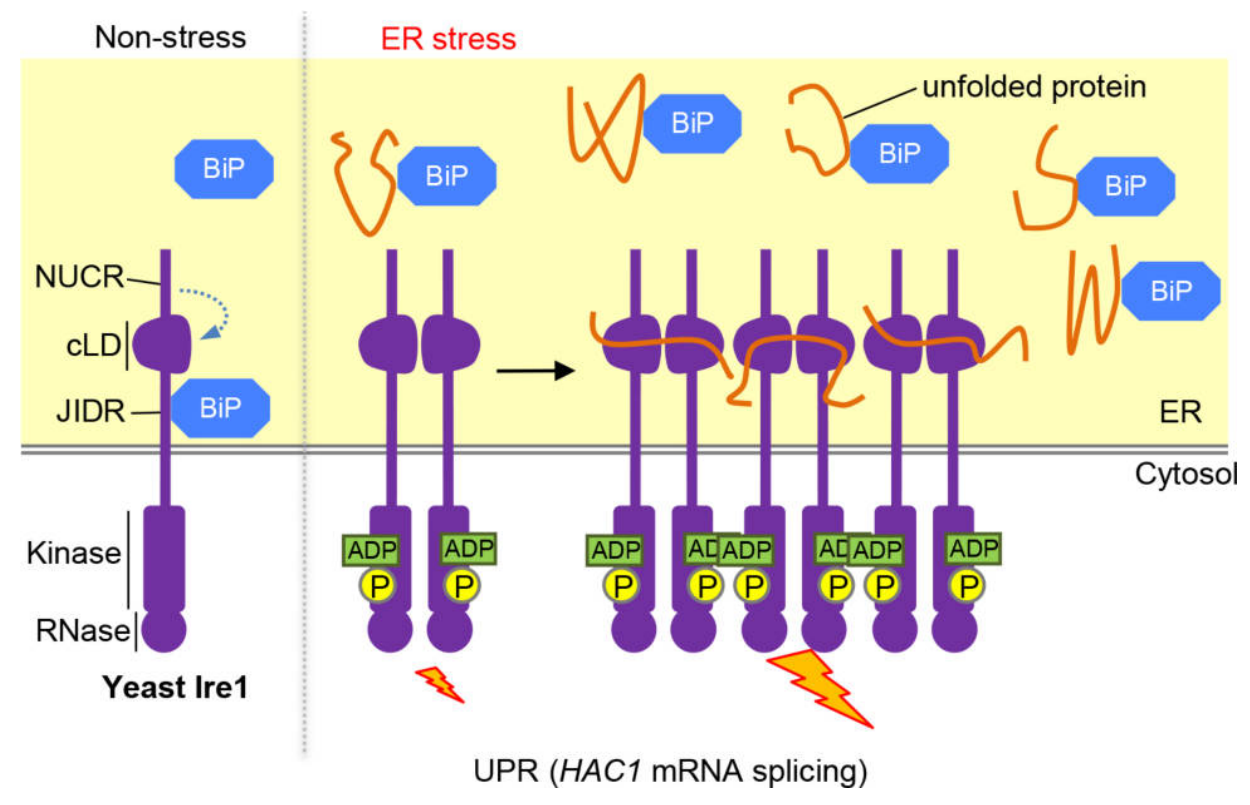

Fig. 3. Our model for upregulation of Ire1 upon ER accumulation of unfolded proteins in yeast cells. Under non-stress conditions, the JIDR (the BiPbinding site) and the NUCR inhibit the self-association of Ire1. Upon ER stress, BiP is dissociated from Ire1, which is then dimerized. The Ire1 dimers are automatically phosphorylated and then captures ADP for their activation as RNase. Meanwhile, the Ire1 dimers directly captures ER-accumulated unfolded proteins and are further bundled, leading to more potent UPR.

The multistep regulatory events on the ER-luminal side described so far are documented in more detail in our previous review articles (Kimata and Kohno 2011; IshiwataKimata et al., 2018), and are likely to contribute to the tight regulation of the UPR. Probably because a number of genes are directly or indirectly controlled by Irel and $\mathrm{HACl}$ (Travers et al., 2000; Kimata et al., 2006), yeast cells expressing less tightly regulated mutant versions of Ire1 grew slowly (Mathuranyanon et al., 2015; Le et al. 2021). Therefore, it should be important that Ire1 activity is quickly attenuated under the post-ER-stress phase of yeast cells. Ire1 mutants not carrying the JIDR were shown to be poorly downregulated when yeast cells were recovering from ER-stress conditions after a transient UPR evocation (Pincus et al., 2010; Ishiwata-Kimata et al., 2013a). This observation strongly suggests that the Ire1 re-association with $\mathrm{BiP}$ largely contributes to the attenuation of its activity.

As aforementioned, auto-phosphorylation of yeast Ire1 leads to its activation as an RNase (Shamu and Walter, 1996; Lee et al., 2008). While, to promote a phosphotransfer reaction, a kinase carries a nucleotide-binding pocket (NBP) to which ATP binds, the NBP of Ire1 has another function. The NBP of auto-phosphorylated Ire1 captures ADP, leading to a further conformational change in the cytosolic moiety of Ire1, which then exhibits higher activity as an RNase (Lee et al., 2008; Korennykh et al., 2009; Korennykh et al., 2011). In other words, ADP serves as an activation ligand of Ire1. Intriguingly, kinase-dead mutants of Ire 1 are thus able to splice $H A C l$ mRNA and to induce the UPR in yeast cells when undergone a similar conformational change (Papa et al., 2003; Chawla et al., 2011; Rubio et al., 2011). According to our recent observation, an Ire 1 mutant that is activated without undergoing these kinase domain-dependent regulatory events was hypersensitive to ER stress, suggesting a role of the kinase domain for fine tuning of the UPR level (Le et al., 2021).We assume that under mild ER-stress conditions, Ire1 is activated only weakly, partly because cells are healthy enough to perform ATP biogenesis normally, keeping a low cytosolic ADP level. In contrast, strong ERstressing stimuli severely damage cells, elevating cytosolic ADP level and eventually activating Ire1 strongly (Le et al., 2021).

Membrane-lipid biogenesis is another important role of the ER. Cox et al. (1997) exhibited an UPR induction by depletion of inositol, which is an important constituent of membrane lipid, from yeast culture. To our knowledge, this was the first report to argue that a membrane lipid-related abnormality causes ER stress and activates Ire1. Moreover, saturation of membrane lipids is now known to be an ERstressing stimulus in yeast and mammalian cells (Pineau and Ferreira, 2010). Ire1 is also activated by imbalanced composition of hydrophilic moieties of phospholipids (low phosphatidyl choline (PC) and high phosphatidyl ethanolamine) in yeast cells (Thibault et al., 2012). Micoogullari et al. (2020) reported a UPR induction upon defects of the very-long-chain fatty acid (VLCFA) metabolism. We think 
that induction of the UPR when yeast cells are confronted with these membrane lipid-related abnormalities is a reasonable cellular response, because the Ire1-HACl pathway transcriptionally induces a large number of genes including those encoding enzymes that work for metabolism of membrane lipids or inositol (Travers et al., 2000; Kimata et al., 2006).

In yeast cells, defects in the PC biogenesis or the VLCFA metabolism lead to saturation of the fatty-acid moieties of phospholipids (Boumann et al., 2006; Micoogullari et al., 2020). Therefore, it is possible that membrane lipid-related abnormalities, which is now collectively called the lipid bilayer stress (LBS), activate Ire1 commonly via membrane-lipid saturation. Mutation analyses of yeast Ire1 demonstrated that LBS and ER accumulation of unfolded proteins are different types of ER-stressing stimuli that activate Ire1 in different ways (Promlek et al., 2011; Halbleib et al., 2017; Tran et al., 2019, Ho et al., 2020). According to Promlek et al. (2011) and Ho et al. (2020), the ER-luminal moiety of Ire1 is dispensable for UPR induction in response to LBS. An in vitro experiment described by Volmer et al. (2013) showed that the autophosphorylation degree of recombinant fragments of IRE1 $\alpha$ or PERK was enhanced when they were incorporated into liposomes highly containing saturated phospholipids. It is thus likely that Ire1 orthologues and PERK directly sense the saturation degree of membrane lipids. The short transmembrane helix (TMH) of yeast Ire1 is juxtaposed to an amphipathic helix (AH), which contributes to LBS sensing (Fig. 4; Halbleib et al., 2017; Tran et al., 2019; Ho et al., 2020). According to Halbleib et al. (2017) and Covino et al. (2018), because of this unique structure, Ire1 molecules compress the lipid bilayer, and gather upon LBS (Fig. 4). Unlike the case of robust accumulation of unfolded proteins in the ER, Ire1 does not seem to cluster upon LBS (Ho et al., 2020).

However, it may also be possible that disturbance of the membrane-lipid homeostasis worsens the protein-folding status in the ER, leading to the UPR evocation. Shyu Jr et al. (2019) reported that, in yeast cells, LBS causes destabilization and degradation of ER-resident transmembrane proteins, which may further damage the ER.

One question emerging from these insights is what (LBS or ER accumulation of unfolded proteins) mediates Ire1 activation by a stressing stimulus. This question can be answered using Ire1 mutants that are impaired in one of the aforementioned stress-sensing mechanisms. The thiolreducing reagent dithiothreitol (DTT) has been believed to activate Irel by damaging the protein-folding status of ER-client proteins. However, it is also likely that LBS is partially involved in the DTT-induced UPR evocation in yeast cells (Halbleib et al., 2017; Tran et al., 2019). According to Reinhard et al. (2020), the unsaturation level of membrane lipids is decreased when yeast cells are exposed to DTT. Another intriguing example is ethanol,
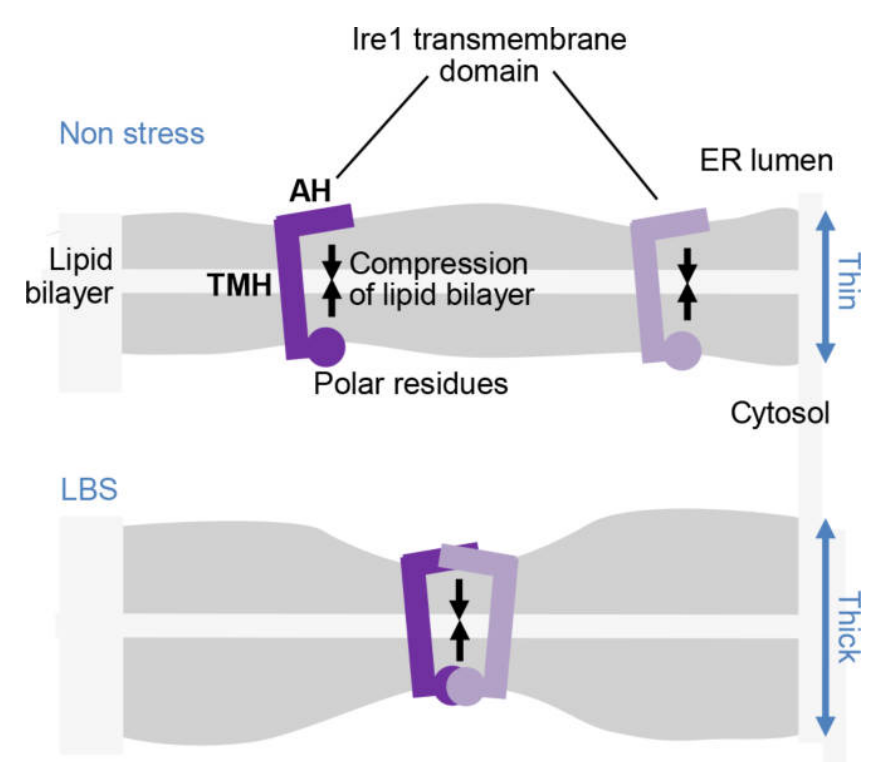

Fig. 4. Possible involvement of the Ire1 transmembrane-domain structure in the activation of Ire1 upon LBS. The short TMH of Ire1 is juxtaposed $\mathrm{N}$-terminally to the $\mathrm{AH}$ and $\mathrm{C}$-terminally to polar residues, causing compression of the lipid bilayer (Halbleib et al., 2017; Covino et al., 2018). When the lipid-bilayer structure is disturbed, for example, through membrane-lipid saturation, free energy cost for the lipid-bilayer compression by the Ire1 transmembrane domain is increased. Ire1 molecules are then gathered to cope with this situation.

which induces ER stress in animal and yeast cells (Miyagawa et al., 2014; Yang and Luo, 2015). It is likely that ethanol causes both protein denaturation and membrane fluidification (Miyagawa et al., 2014; Navarro-Tapia et al., 2018). According to mutation analysis of yeast Ire1 (Tran et al., 2019), ethanol activates Ire1 via both LBS and ER accumulation of unfolded proteins.

\section{Stress-sensing and regulatory mechanism of IRE1 $\alpha$ and PERK}

As well as yeast Ire1, the vertebrate Ire1 paralogues, IRE1 $\alpha$ and IRE1 $\beta$, and PERK are ER-located type-I transmembrane proteins. On the luminal side, they commonly carry weakly but significantly homologous cLD sequences (Fig. 1). Therefore, one may assume that they are controlled similarly to yeast Ire1. Hereafter, this review discusses if this assumption is true or not.

Bertolotti et al. (2000) demonstrated that in mammalian cells, BiP is associated with IRE1 $\alpha$ (and also IRE1 $\beta$ ), whereas the heteromeric complexes are dissociated in response to ER stress. Similarly to yeast Ire1, IRE1 $\alpha$ carries the JIDR, which is dispensable for its activity (Fig. 1; Oikawa et al., 2009). Albeit partly, a deletion mutation of the JDIR compromised the BiP association with IRE1 $\alpha$ and 
(A)

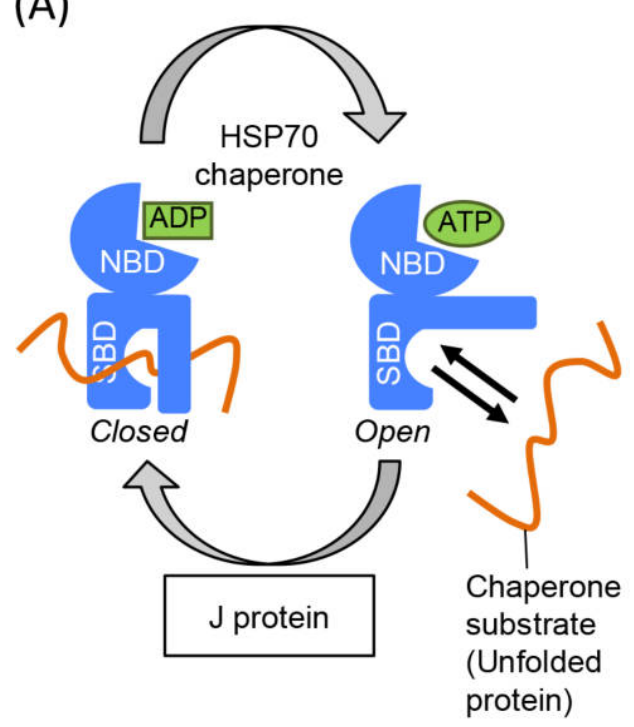

(B)

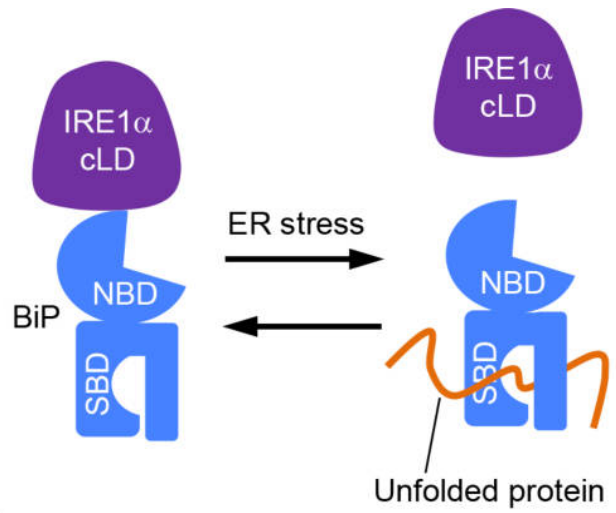

(C)

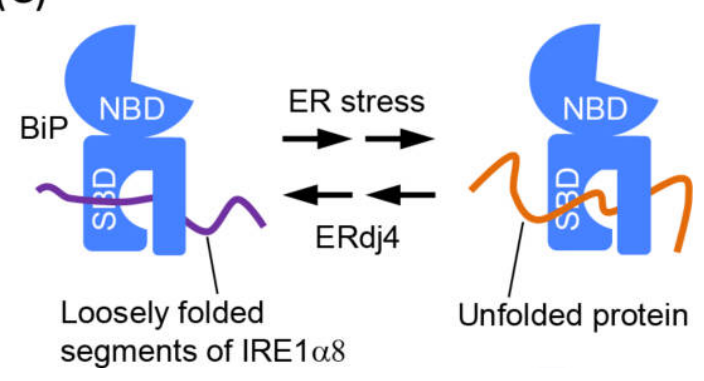

Fig. 5. Relationship between BiP and Ire1. (A) In general, the HSP70-family molecular chaperones capture client substrate proteins dependently on its nucleotide-binding states. (B) and (C) As described in the main text, two theories are proposed to explain the association/dissociation mode between IRE1 $\alpha$ and ER-accumulated unfolded proteins. Nucleotides bound to BiP are not shown in panels B and C.

activated IRE1 $\alpha$ (Oikawa et al., 2009). This observation suggests a role of $\mathrm{BiP}$ as a negative regulator of IRE1 $\alpha$. Meanwhile, it is likely that BiP is also targeted on the cLD (Carrara et al., 2015b; Amin-Wetzel et al., 2019).

As reviewed in Behnke et al. (2015), BiP is the ERlocated version of the HSP70-family molecular chaperone, which is composed of the nucleotide-binding domain (NBD) and the substrate-binding domain (SBD). In general, association between the HSP70-family chaperone and unfolded-protein substrates is regulated by the ATPase cycle (Fig. 5A). When ATP is bound to the NBD, the SBD is the "open" form, which captures and releases substrate peptides rapidly. $\mathrm{J}$ proteins promote hydrolysis of ATP bound to the NBD, and turn the SBD into the "closed" form, which tightly captures substrate proteins. It is also widely accepted that a $\mathrm{J}$ protein facilitates the interaction between a HSP70-family chaperone and a specific chaperone substrate(s). Through the nucleotide exchange on the NBD (from ADP to ATP), the SBD returns to the "open" form.

Recently, the interaction between BiP and IRE1 $\alpha$ has been more deeply investigated, which has led to two controversial theories. Carrara et al. (2015b) reconstituted the BiP-cLD heteromeric complex, the formation of which was abolished in the presence of a model unfolded peptide, in their in vitro experiments. According to the observations from this and the following studies (Carrara et al., 2015b;
Kopp et al., 2018; Kopp et al., 2019), IRE1 $\alpha$ is not a chaperone substrate of BiP, but binds to the NBD of BiP. As illustrated in Fig. 5B, this allosteric regulation model argues that the BiP NBD is dissociated from IRE1 $\alpha$ when its SBD captures unfolded-protein substrates. Todd-Corlett et al. (2007) suggested that yeast Ire1 also binds to the NBD of BiP.

In contrast, the observations presented in Amin-Wetzel et al. (2019) strongly suggest that IRE1 $\alpha$ is a chaperone substrate of BiP. The cLD carries a loosely folded segment, to which BiP binds (Amin-Wetzel et al., 2019). According to this theory, IRE $1 \alpha$ is dissociated from BiP upon ER stress through competition against unfolded proteins for $\mathrm{BiP}$ binding (Fig. 5C). While in mammalian cells, the ER contains various $\mathrm{J}$ proteins, among them, ERdj4 specifically acts to facilitate the interaction between IRE1 $\alpha$ and BiP (Amin-Wetzel et al., 2017; Amin-Wetzel et al., 2019).

In both the allosteric and competition models, BiP, but not IRE1 $\alpha$ per se, is the direct sensor for unfolded proteins that is responsible for activation of IRE1 $\alpha$ upon ER stress. Alongside BiP dissociation, IRE1 $\alpha$ is self-associated (probably dimerized) to evoke the downstream events. Zhou et al. (2006) and Oikawa et al. (2009) argued against the direct physical interaction between unfolded proteins and the cLD of IRE1 $\alpha$. According to the X-ray crystal structure analysis presented by Zhou et al. (2006), the groove-like structure of the IRE1 $\alpha$ luminal domain is too narrow to 


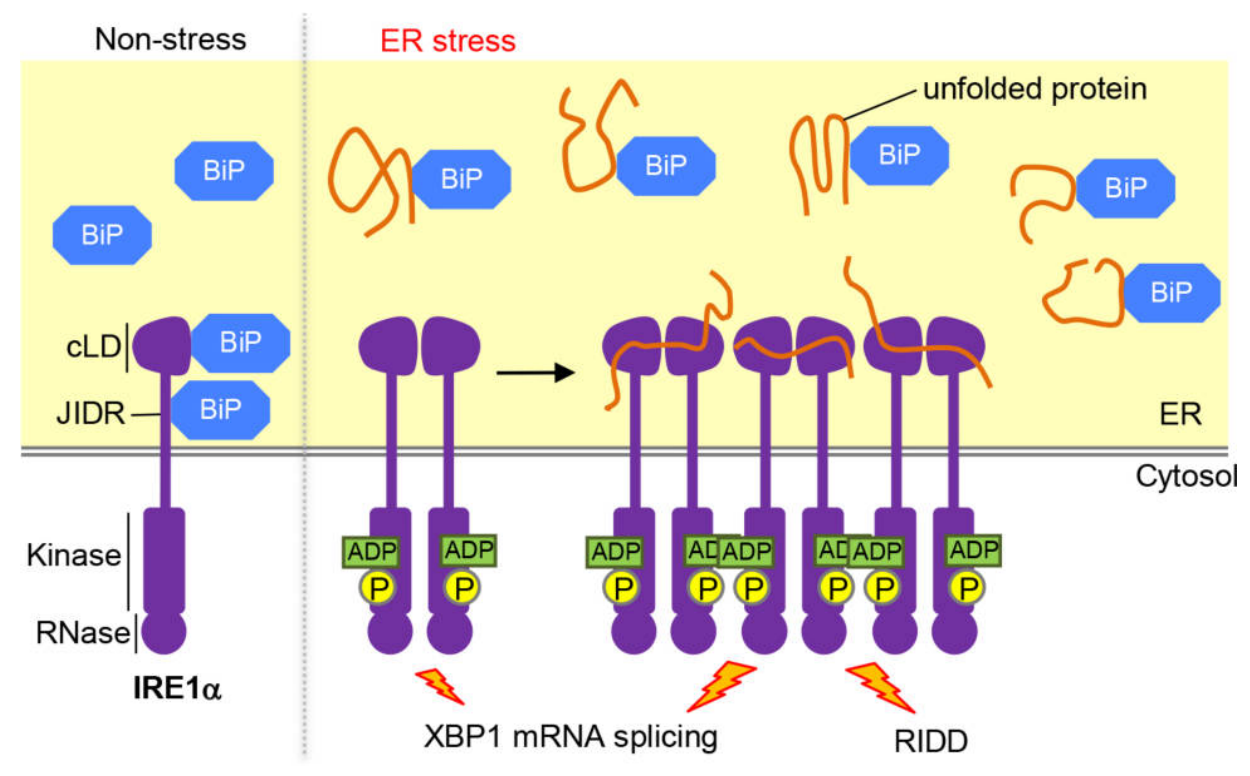

Fig. 6. A possible model to explain how IRE1 $\alpha$ is activated upon ER accumulation of unfolded proteins in animal cells. Under non-stress conditions, BiP is bound to the cLD and JIDR of IRE1 $\alpha$, which then stays non-self-associated. Upon ER accumulation of unfolded proteins, IRE1 $\alpha$ dissociates from BiP and forms homo-dimers. It is uncertain if IRE1 $\alpha$ and unfolded proteins bind to the same site of BiP. Similarly to those of yeast Ire1, IRE1 $\alpha$ dimers are further bundled through their direct interaction with unfolded proteins. As described in the main text, it is possible that IRE1 $\alpha$ dimers and oligomers have distinct biological functions.

directly capture unfolded proteins. Amin-Wetzel et al. (2017) reported that IRE1 $\alpha$ is considerably activated in non-stressed mammalian cells when its association with $\mathrm{BiP}$ is impaired. In this context, BiP may be the principal regulator of IRE1 $\alpha$.

Meanwhile, Li et al. (2010) and Belyy et al. (2020) noted the ER stress-dependent cluster formation of IRE1 $\alpha$, together with its dissociation under the post-ER-stress phase, in mammalian cells. How is this process promoted and regulated? In contradiction with Zhou et al. (2006) and Oikawa et al. (2009), Karagöz et al. (2017) presented NMR data indicating a conformational shift of the IRE1 $\alpha$ cLD dimers by a model unfolded peptide. Moreover, Sundaram et al. (2018) reported that IRE1 $\alpha$ physically interacts with an ER-accumulated model unfolded protein in mammalian cells. Similarly to the cLD of yeast Ire1, the IRE1 $\alpha$ cLD dimers may be bundled through their direct interaction with unfolded proteins (Karagöz et al., 2017). Meanwhile, a model unfolded peptide was shown not to directly stimulate the dimerization of the luminal domain of IRE1 $\alpha$ (AminWetzel et al., 2019). It is thus likely that free IRE1 $\alpha$ cLD molecules are spontaneously dimerized, whereas oligomerization of the IRE1 $\alpha$ cLD dimers is promoted by unfolded proteins.

Therefore, it is assumed that, while not carrying the NUCR (Fig. 1), IRE1 $\alpha$ senses ER stress and is regulated in a fashion similar to that of yeast Ire1 as follows (Fig. 6). Under normal conditions, IRE1 $\alpha$ is associated with $\mathrm{BiP}$ and remains non-self-associated. In response to ER stress, ER- accumulated unfolded proteins cause the dissociation of BiP from IRE1 $\alpha$, which then self-dimerizes (Bertolotti et $a l ., 2000)$. The dimerized IRE1 $\alpha$ molecules directly capture unfolded proteins and are further oligomerized. Meanwhile, the cluster formation of IRE1 $\alpha$ cannot be explained solely by the cLD oligomerization. According to Ricci et al. (2019), IRE1 $\alpha$ clusters dependently on the autophosphorylation of its cytosolic moiety.

It should also be noted that IRE1 $\alpha$ undergoes regulatory processes that have not been reported in the case of yeast Ire1. Eletto et al. (2014) proposed that IRE1 $\alpha$ stably oligomerizes through its intramolecular disulfide-bond formation, which is cleaved by protein disulfide isomerase A6. Moreover, as reviewed by Hetz and Papa (2018), various proteins other than $\mathrm{BiP}$ have been reported to physically interact with and control IRE1 $\alpha$. One example is HSP47, which is known as the ER-located and collagen-specific molecular chaperone (Ito and Nagata, 2019). According to Sepulveda et al. (2018), the physical interaction between HSP47 and IRE1 $\alpha$ promotes the dissociation of BiP from IRE $1 \alpha$ and facilitates the self-association of IRE1 $\alpha$. In other words, HSP47 can serve as a positive regulator of IRE1 $\alpha$.

BiP is also associated with PERK. ER stress causes BiP dissociation from PERK, which seems to be linked to the self-oligomerization of PERK (Bertolotti et al., 2000). As well as that of yeast Ire1, the luminal domain of PERK carries the NUCR and the JIDR, which function to downregulate PERK (Fig. 1; Ma et al., 2002; Mathuranyanon et al., 
2015). In mammalian cells, the BiP association with PERK is almost completely abolished by a JIDR-deletion mutation of PERK (Ma et al., 2002). Therefore, it is likely that BiP binds to the JIDR of PERK, which then remains nonself-associated, in unstressed cells. Meanwhile, an in vitro study performed by Carrara et al. (2015b) showed a physical interaction between BiP and the PERK cLD, which is inhibited by unfolded proteins. X-ray crystal structure analyses indicated PERK cLD's tetrameric self-association, which contributes to the activation of PERK (Carrara et al., 2015a; Wang et al., 2016). Moreover, the PERK cLD has the ability to associate with unfolded proteins (Wang et al., 2016), the biological meaning of which remains obscure. Taken together, although its binding site is not yet determined, BiP serves as a negative regulator of PERK and dissociates from PERK in response to ER stress. It is uncertain if the direct interaction between the PERK cLD and unfolded proteins contributes to the oligomerization and activation of PERK.

Even with mutations for deletion of their luminal domains, IRE1 $\alpha$ and PERK responded to LBS that causes membrane-lipid saturation (Volmer et al., 2013). This observation is consistent with the aforementioned insights from yeast Ire1 (Promlek et al., 2011; Ho et al., 2020). Halbleib et al. (2017) speculated that the scenario shown in Fig. 4 is also applicable to IRE1 $\alpha$ and PERK, which, similarly to the yeast Ire1, carry AH sequences that are juxtaposed to TMH sequences. However, according to Kono et al. (2017), the AH sequence is dispensable for the activation of IRE1 $\alpha$ by membrane-lipid saturation. It is therefore still obscure how LBS is sensed by the metazoan ER-stress sensors.

\section{Stress-sensing and regulatory mechanism of ATF6}

Vertebrate species carry two ATF6 paralogues, namely ATF6 $\alpha$ and ATF6 $\beta$. Since the double knockout mutation of ATF $6 \alpha$ and ATF6 $\beta$, but not single knockout of either of the paralogues, of mouse causes embryonic lethality (Yamamoto et al., 2007), they are, at least partly, functionally redundant. Meanwhile, the gene knockout study also indicated that ATF6 $\alpha$, but not ATF6 $\beta$, is responsible for the transcriptional induction of ER quality control proteins (Yamamoto et al., 2007). According to Thuerauf et al. (2004), the cytosolic segment of ATF6 $\alpha$ acts as a transcription activator more strongly than that of ATF6 $\beta$. It thus sounds rational that ATF6 $\alpha$ were mainly employed to obtain the undermentioned insights concerning the activation mechanism of ATF6.

ATF6, a type-II transmembrane protein (Fig. 7), exhibits no sequence similarity to Ire1 or PERK, which are type-I transmembrane proteins. Therefore, it seems reasonable to assume that the regulation mechanism of ATF6 is com- pletely different from that of Ire 1 and PERK. However, as will be described later, it is also likely that, similarly to Ire1 and PERK, ATF6 is negatively regulated by BiP.

As aforementioned, ATF6 is retained in the ER of unstressed cells, and is transported to the Golgi apparatus, which carries the S1P and S2P proteases, in response to ER stress (Fig. 7; Ye et al., 2000; Chen et al., 2002; Shen et al., 2002). ATF6 is then cleaved by these proteases to yield the soluble transcription activator ATF6(N) (Fig. 7; Haze et al., 1999; Ye et al., 2000). The regulated ER-to-Golgi transport is thus the key step for the ER stress-dependent activation of ATF6. According to Sato et al. (2011), the C-terminal luminal fragment of ATF6 (ATF6(C); "C" stands for "Cterminal") underwent the regulated ER-to-Golgi transport in response to ER stress, even when it was produced in the ER of mammalian cells as a soluble protein. This observation indicates that the C-terminal luminal moiety of ATF6 alone is sufficient for sensing ER stress. The coat protein complex II (COPII) functions to bring out proteins from the ER for their transportation to the Golgi apparatus (Venditti et al., 2014). An in vitro research performed by Schindler and Schekman (2009) reconstituted the COPII-dependent incorporation of ATF6 and ATF6(C) into membrane vesicles, which was stimulated by DTT.

Shen et al. (2002) indicated that ATF6 forms a heterocomplex with $\mathrm{BiP}$, which is dissociated in response to ER stress. An ATF6 mutant that cannot bind to BiP was constitutively transported to the Golgi apparatus and cleaved (Shen et al., 2002). Although this observation strongly suggests a role of $\mathrm{BiP}$ as a negative regulator of ATF6, it should also be noted that ATF6 luminal-domain mutations can affect the disulfide bond-formation status of ATF6, which, as described later, controls the ER-to-Golgi transport of ATF6. According to Shen et al. (2005), the ATF6BiP complex is stable and does not carry out the association/dissociation cycle shown in Fig. 5A. This insight implies that the diminishment of the ATF6-BiP complex upon ER stress is not a result from simple competition between ATF6 and ER-accumulated unfolded proteins for binding to BiP. It thus remains unclear how ER stress leads to the dissociation of ATF6 from BiP.

Another topic is the disulfide-bond formation of ATF6. Schindler and Schekman (2009) showed that DTT leads ATF6 to dissociate from BiP and to exit from the ER in permeabilized cells. It is therefore possible that the protein redox state in the ER may directly affect the activation steps of ATF6. Compared to IRE1 $\alpha$ or PERK, ATF6 seemed to respond to DTT-induced stress more efficiently than to other types of ER-stressing stimuli (DuRose et al., 2006; Nadanaka et al., 2007). According to Nadanaka et al. (2007) and Koba et al. (2020), ATF6 molecules are intermolecularly bridged by disulfide bonds to form self-dimers, or contain intramolecular disulfide bonds (Fig. 7). ER stress leads to reduction of the disulfide bonds of ATF6, which contributes to the activation of ATF6 (Fig. 7; Nadanaka et 


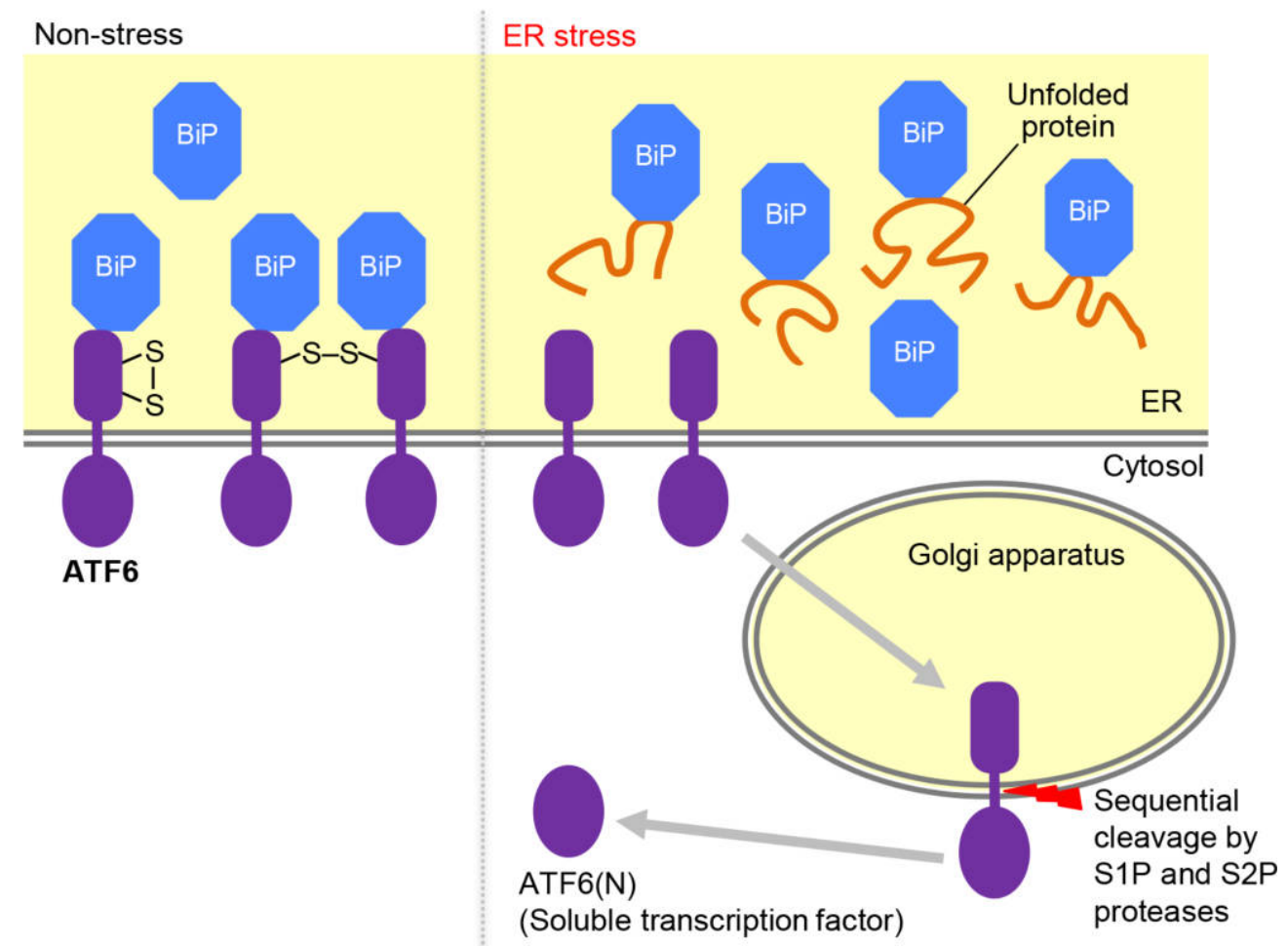

Fig. 7. Activation process of ATF6. In non-stressed cells, ATF6 is retained in the ER as BiP-bound and oxidized forms. Upon ER stress, ATF6 dissociates from BiP and is reduced (cleavage of the disulfide bonds). The monomeric ATF6 proteins are then transported to the Golgi apparatus and proteolytically cleaved.

al. 2007; Oka et al., 2019).

It is therefore possible that ATF6 acts as a sensor for the ER redox status. One counterargument against this idea comes from the fact that ATF6 is reduced not only by DTTinduced stress but also in response to other ER-stressing stimuli that do not seem to directly alter the ER redox status (Nadanaka et al., 2006; Nadanaka et al., 2007). The ER may have a sophisticated machinery that stimulates the ATF6 reduction in response to ER stress even without global variation in the ER redox status. Indeed, according to Oka et al. (2019), an ER-resident oxidoreductase, ERp18, transiently associates with ATF6 $\alpha$ upon ER stress, assisting the activation of ATF6. The protein disulfide isomerase A5 is also likely to contribute to the reduction and activation of ATF6 (Higa et al., 2014). Meanwhile, it should also be noted that the ability of the ER to form protein disulfide bonds can be impaired commonly by ERstressing stimuli including those that do not seem to directly lead to the reduction of ER proteins (Merksamer et al., 2008).

How does the reduction of ATF6 lead to its activation as a soluble and active transcription factor? Nadanaka et al. (2007) proposed that the ATF6 reduction contributes to (but is not sufficient for) its transport to the Golgi apparatus. An observation contradicting this scenario is that the ER-toGolgi transport of ATF6 was promoted by the ERp18 knockout mutation (Oka et al., 2019). Meanwhile, it is also likely that the ATF6 reduction is required for its correct cleavage in the Golgi apparatus (Nadanaka et al., 2007; Oka et al., 2019). Fig. 7 shows a current model for the activation of ATF6 in response to ER stress. In agreement with this model, Sundaram et al. (2018) reported that ER stress deceases the oligomerization size (homo- or heterooligomers) of ATF6.

Similarly to the Ire1 orthologues and PERK, ATF6 may sense LBS through a molecular mechanism different from that for the sensing of disturbance in ER protein folding. Tam et al. (2018) reported the activation of ATF6 by cellular treatment with dihydrosphingosine and dihydroceramide. In this case, the stress-sensing module is likely to lie not on the luminal domain but on the transmembrane domain of ATF6 (Tam et al., 2018).

\section{Conclusion and future perspective}

As described here, yeast Ire1 is controlled in multiple fashions, which include negative regulation by $\mathrm{BiP}$ and the direct capturing of unfolded proteins. Although seemingly 
understood better than that of IRE1 $\alpha$, the regulation mechanisms of yeast Ire1 still present unresolved questions. For instance, it remains unclear how yeast Irel escapes from repression by $\mathrm{BiP}$ upon LBS. It is also possible that yeast Ire1 undergoes an as-yet undisclosed regulatory event. For instance, according to Wiseman et al. (2010), the cytosolic domain of yeast Ire1 has a putative ligand-binding pocket that can control its RNase activity.

Regulatory processes for IRE1 $\alpha$ seem to be more complicated than those for yeast Ire1, and remains controversial points. It should be determined in future to what extent the direct interaction between IRE1 $\alpha$ and unfolded proteins contributes to the regulation of IRE1 $\alpha$ in response to ER stress. Besides, unlike yeast Ire1, IRE1 $\alpha$ proximately evokes multiple events, including the RIDD and the XBP1mRNA splicing. Moreover, not only the RNase activity but also the kinase activity of IRE1 $\alpha$ is likely to directly act to induce downstream events in mammalian cells (Urano et al., 2000; Nishitoh et al., 2002; Ali et al., 2011; Hetz and Papa, 2018).

Intriguingly, the activities of IRE1 $\alpha$ to promote RIDD and XBP1-mRNA splicing are differently regulated (Han et $a l ., 2009)$. One scenario is that dimerized IRE1 $\alpha$ molecules perform only XBP1-mRNA splicing, whereas further oligomerization of IRE1 $\alpha$ is required for its RIDD activity (Han et al., 2009; Ghosh et al., 2014; Bashir et al., 2020). Whereas XBP1-mRNA splicing by IRE1 $\alpha$ mainly acts cytoprotectively, RIDD can trigger apoptosis, for instance, through the digestion of microRNAs that repress translation of the mRNA encoding Caspase 2, an apoptosis initiator (Upton et al., 2012; Maurel et al., 2014). Although other scenarios are also possible (Iurlaro and Muñoz-Pinedo, 2016; Bashir et al., 2020), these insights explain a mechanism for apoptosis induction by strong and chronic ER stress. That is, although mild ER stress leads only to the dimerization of IRE1 $\alpha$, which eventually rescues the cells, strong and chronic ER stress causes severe accumulation of unfolded proteins in the ER, which triggers the proapoptotic RIDD through high-order oligomerization of IRE1 $\alpha$. Moreover, the regulatory mechanism of IRE1 $\alpha$ 's ability to phosphorylate other proteins is another interesting question, since, as aforementioned, IRE1 $\alpha$ is likely to act as a kinase but not as an RNase for activation of JNKs, which also leads to apoptosis (Sano and Reed, 2013).

Another implication of the insights described so far is that, although collectively called ER-stress sensors, IRE1 $\alpha$, PERK, and ATF6 sense stressing stimuli and are regulated in different manners. We think that this issue can be a molecular basis for activating these proteins on different timelines in ER-stressed cells (Yoshida et al., 2003). Moreover, these ER-stress sensors carry out different physiological roles in multicellular organisms (Mitra and Ryoo, 2019), probably and partly because they are regulated differently.

\section{References}

Ali, M.M.U., Bagratuni, T., Davenport, E.L., Nowak, P.R., SilvaSantisteban, M.C., Hardcastle, A., McAndrews, C., Rowlands, M.G., Morgan, G.J., Aherne, W., Collins, I., Davies, F.E., and Pearl, L.H. 2011. Structure of the Ire1 autophosphorylation complex and implications for the unfolded protein response. EMBO J., 30: 894-905.

Amin-Wetzel, N., Saunders, R.A., Kamphuis, M.J., Rato, C., Preissler, S., Harding, H.P., and Ron, D. 2017. A J-Protein Co-chaperone Recruits BiP to Monomerize IRE1 and Repress the Unfolded Protein Response. Cell, 171: 1625-1637.

Amin-Wetzel, N., Neidhardt, L., Yan, Y., Mayer, M.P., and Ron, D. 2019. Unstructured regions in IRE1alpha specify BiP-mediated destabilisation of the luminal domain dimer and repression of the UPR. eLife, 8: e. 50793.

Aragón, T., van Anken, E., Pincus, D., Serafimova, I.M., Korennykh, A.V., Rubio, C.A., and Walter, P. 2009. Messenger RNA targeting to endoplasmic reticulum stress signalling sites. Nature, 457: 736-740.

Bashir, S., Banday, M., Qadri, O., Bashir, A., Hilal, N., Nida-I-Fatima, Rader, S., and Fazili, K.M. 2020. The molecular mechanism and functional diversity of UPR signaling sensor IRE1. Life Sci., 265: 118740.

Behnke, J., Feige, M.J., and Hendershot, L.M. 2015. BiP and its nucleotide exchange factors Grp170 and Sil1: mechanisms of action and biological functions. J. Mol. Biol., 427: 1589-1608.

Belyy, V., Tran, N.H., and Walter, P. 2020. Quantitative microscopy reveals dynamics and fate of clustered IRE1alpha. Proc. Natl. Acad. Sci. USA, 117: 1533-1542.

Bertolotti, A., Zhang, Y., Hendershot, L.M., Harding, H.P., and Ron, D. 2000. Dynamic interaction of BiP and ER stress transducers in the unfolded-protein response. Nat. Cell Biol., 2: 326-332.

Boumann, H.A., Gubbens, J., Koorengevel, M C., Oh, C.S., Martin, C.E., Heck, A.J., Patton-Vogt, J., Henry, S.A., de Kruijff, B., and de Kroon, A.I. 2006. Depletion of phosphatidylcholine in yeast induces shortening and increased saturation of the lipid acyl chains: evidence for regulation of intrinsic membrane curvature in a eukaryote. Mol. Biol. Cell, 17: $1006-1017$.

Calfon, M., Zeng, H., Urano, F., Till, J.H., Hubbard, S.R., Harding, H.P., Clark, S.G., and Ron, D. 2002. IRE1 couples endoplasmic reticulum load to secretory capacity by processing the XBP-1 mRNA. Nature, 415: 92-96.

Carrara, M., Prischi, F., Nowak, P.R., and Ali, M.M. 2015a. Crystal structures reveal transient PERK luminal domain tetramerization in endoplasmic reticulum stress signaling. EMBO J., 34: 1589-1600.

Carrara, M., Prischi, F., Nowak, P.R., Kopp, M.C., and Ali, M.M. 2015b. Noncanonical binding of BiP ATPase domain to Ire1 and Perk is dissociated by unfolded protein $\mathrm{CH} 1$ to initiate ER stress signaling. eLife, 4 : e03522.

Chawla, A., Chakrabarti, S., Ghosh, G., and Niwa, M. 2011. Attenuation of yeast UPR is essential for survival and is mediated by IRE1 kinase. $J$. Cell Biol., 193: 41-50.

Chen, X., Shen, J., and Prywes, R. 2002. The luminal domain of ATF6 senses endoplasmic reticulum (ER) stress and causes translocation of ATF6 from the ER to the Golgi. J. Biol. Chem., 277: 13045-13052.

Covino, R., Hummer, G., and Ernst, R. 2018. Integrated functions of membrane property sensors and a hidden side of the unfolded protein response. Mol. Cell, 71: 458-467.

Cox, J.S., Shamu, C.E., and Walter, P. 1993. Transcriptional induction of genes encoding endoplasmic reticulum resident proteins requires a transmembrane protein kinase. Cell, 73: 1197-1206.

Cox, J.S. and Walter, P. 1996. A novel mechanism for regulating activity of a transcription factor that controls the unfolded protein response. Cell, 87: 391-404.

Cox, J.S., Chapman, R.E., and Walter, P. 1997. The unfolded protein 
response coordinates the production of endoplasmic reticulum protein and endoplasmic reticulum membrane. Mol. Biol. Cell, 8: 1805-1814.

Credle, J.J., Finer-Moore, J.S., Papa, F.R., Stroud, R.M., and Walter, P. 2005. On the mechanism of sensing unfolded protein in the endoplasmic reticulum. Proc. Natl. Acad. Sci. USA, 102: 18773-18784.

Donnelly, N., Gorman, A.M., Gupta, S., and Samali, A. 2013. The eIF2 $\alpha$ kinases: their structures and functions. Cell. Mol. Life Sci., 70: $3493-$ 3511.

DuRose, J.B., Tam, A.B., and Niwa, M. 2006. Intrinsic capacities of molecular sensors of the unfolded protein response to sense alternate forms of endoplasmic reticulum stress. Mol. Biol. Cell, 17: 3095-3107.

Eletto, D., Eletto, D., Dersh, D., Gidalevitz, T., and Argon, Y. 2014. Protein disulfide isomerase A6 controls the decay of IRE1 $\alpha$ signaling via disulfide-dependent association. Mol. Cell, 53: 562-576.

Gardner, B.M. and Walter, P. 2011. Unfolded proteins are Ire1-activating ligands that directly induce the unfolded protein response. Science, 333: 1891-1894.

Ghosh, R., Wang, L., Wang, E.S., Perera, B.G., Igbaria, A., Morita, S., Prado, K., Thamsen, M., Caswell, D., Macias, H., Weiberth, K.F., Gliedt, M.J., Alavi, M.V., Hari, S.B., Mitra, A.K., Bhhatarai, B., Schürer, S.C., Snapp, E.L., Gould, D.B., German, M.S., Backes, B.J., Maly, D.J., Oakes, S.A., and Papa, F.R. 2014. Allosteric inhibition of the IRE1 $\alpha$ RNase preserves cell viability and function during endoplasmic reticulum stress. Cell, 158: 534-548.

Grey, M.J., Cloots, E., Simpson, M.S., LeDuc, N., Serebrenik, Y.V., De Luca, H., De Sutter, D., Luong, P., Thiagarajah, J.R., Paton, A.W., Paton, J.C., Seeliger, M.A., Eyckerman, S., Janssens, S., and Lencer, W.I. 2020. IRE1 $\beta$ negatively regulates IRE1 $\alpha$ signaling in response to endoplasmic reticulum stress. J. Cell Biol., 219: e201904048.

Halbleib, K., Pesek, K., Covino, R., Hofbauer, H.F., Wunnicke, D., Hanelt, I., Hummer, G., and Ernst, R. 2017. Activation of the unfolded protein response by lipid bilayer stress. Mol. Cell, 67: 673-684.

Han, D., Lerner, A.G., Vande Walle, L., Upton, J.-P., Xu, W., Hagen, A., Backes, B.J., Oakes, S.A., and Papa, F.R. 2009. IRE1alpha kinase activation modes control alternate endoribonuclease outputs to determine divergent cell fates. Cell, 138: 562-575.

Harding, H.P., Zhang, Y., and Ron, D. 1999. Protein translation and folding are coupled by an endoplasmic-reticulum-resident kinase. Nature, 397: 271-274.

Harding, H.P., Novoa, I., Zhang, Y., Zeng, H., Wek, R., Schapira, M., and Ron, D. 2000. Regulated translation initiation controls stress-induced gene expression in mammalian cells. Mol. Cell, 6: 1099-1108.

Haze, K., Yoshida, H., Yanagi, H., Yura, T., and Mori, K. 1999. Mammalian transcription factor ATF6 is synthesized as a transmembrane protein and activated by proteolysis in response to endoplasmic reticulum stress. Mol. Biol. Cell, 10: 3787-3799.

Hetz, C. and Papa, F.R. 2018. The unfolded protein response and cell fate control. Mol. Cell, 69: 169-181.

Higa, A., Taouji, S., Lhomond, S., Jensen, D., Fernandez-Zapico, M.E., Simpson, J.C., Pasquet, J.M., Schekman, R., and Chevet, E. 2014. Endoplasmic reticulum stress-activated transcription factor ATF6 $\alpha$ requires the disulfide isomerase PDIA5 to modulate chemoresistance. Mol. Cell. Biol., 34: 1839-1849.

Ho, N., Yap, W.S., Xu, J., Wu, H., Koh, J.H., Goh, W.W.B., George, B., Chong, S.C., Taubert, S., and Thibault, G. 2020. Stress sensor Ire1 deploys a divergent transcriptional program in response to lipid bilayer stress. J. Cell Biol., 219: e201909165.

Hollien, J. and Weissman, J.S. 2006. Decay of endoplasmic reticulumlocalized mRNAs during the unfolded protein response. Science, 313: 104-107.

Ishikawa, T., Kashima, M., Nagano, A.J., Ishikawa-Fujiwara, T., Kamei, Y., Todo, T., and Mori, K. 2017. Unfolded protein response transducer IRE1-mediated signaling independent of XBP1 mRNA splicing is not required for growth and development of medaka fish. Elife, 6: e26845.

Ishiwata-Kimata, Y., Promlek, T., Kohno, Y., and Kimata, Y. 2013a. BiPbound and nonclustered mode of Ire1 evokes a weak but sustained unfolded protein response. Genes Cells, 18: 288-301.

Ishiwata-Kimata, Y., Yamamoto, Y.-H., Takizawa, K., Kohno, K., and Kimata, Y. 2013b. F-actin and a type-II myosin are required for efficient clustering of the ER stress sensor Ire1. Cell Struct. Funct., 38: $135-143$.

Ishiwata-Kimata, Y., Le, G.Q., and Kimata, Y. 2018. Stress-sensing and regulatory mechanism of the endoplasmic-stress sensors Ire1 and PERK. Cell Pathology, 5: 1-10. DOI: https://doi.org/10.1515/ ersc-2018-0001

Ito, S. and Nagata, K. 2019. Roles of the endoplasmic reticulum-resident, collagen-specific molecular chaperone Hsp47 in vertebrate cells and human disease. J. Biol. Chem., 294: 2133-2141.

Iurlaro, R. and Muñoz-Pinedo, C. 2016. Cell death induced by endoplasmic reticulum stress. FEBS J., 283: 2640-2652.

Karagöz, G.E., Acosta-Alvear, D., Nguyen, H.T., Lee, C.P., Chu, F., and Walter, P. 2017. An unfolded protein-induced conformational switch activates mammalian IRE1. eLife, 6: e30700.

Kimata, Y., Kimata, Y.I., Shimizu, Y., Abe, H., Farcasanu, I.C., Takeuchi, M., Rose, M.D., and Kohno, K. 2003. Genetic evidence for a role of $\mathrm{BiP} / \mathrm{Kar} 2$ that regulates Ire1 in response to accumulation of unfolded proteins. Mol. Biol. Cell, 14: 2559-2569.

Kimata, Y., Oikawa, D., Shimizu, Y., Ishiwata-Kimata, Y., and Kohno, K. 2004. A role for $\mathrm{BiP}$ as an adjustor for the endoplasmic reticulum stress-sensing protein Ire1. J. Cell Biol., 167: 445-456.

Kimata, Y., Ishiwata-Kimata, Y., Yamada, S., and Kohno, K. 2006. Yeast unfolded protein response pathway regulates expression of genes for anti-oxidative stress and for cell surface proteins. Genes Cells, 11: 5969.

Kimata, Y., Ishiwata-Kimata, Y., Ito, T., Hirata, A., Suzuki, T., Oikawa, D., Takeuchi, M., and Kohno, K. 2007. Two regulatory steps of ERstress sensor Ire1 involving its cluster formation and interaction with unfolded proteins. J. Cell Biol., 179: 75-86.

Kimata, Y. and Kohno, K. 2011. Endoplasmic reticulum stress-sensing mechanisms in yeast and mammalian cells. Curr. Opin. Cell Biol., 23: $135-142$.

Koba, H., Jin, S., Imada, N., Ishikawa, T., Ninagawa, S., Okada, T., Sakuma, T., Yamamoto, T., and Mori, K. 2020. Reinvestigation of disulfide-bonded oligomeric forms of the unfolded protein response transducer ATF6. Cell Struct. Funct., 45: 9-21.

Kono, N., Amin-Wetzel, N., and Ron, D. 2017. Generic membranespanning features endow IRE1 $\alpha$ with responsiveness to membrane aberrancy. Mol. Biol. Cell, 28: 2318-2332.

Kopp, M.C., Nowak, P.R., Larburu, N., Adams, C.J., and Ali, M.M. 2018. In vitro FRET analysis of IRE1 and BiP association and dissociation upon endoplasmic reticulum stress. eLife, 7: e30257.

Kopp, M.C., Larburu, N., Durairaj, V., Adams, C.J., and Ali, M.M.U. 2019. UPR proteins IRE1 and PERK switch BiP from chaperone to ER stress sensor. Nat. Struct. Mol. Biol., 26: 1053-1062.

Korennykh, A.V., Egea, P.F., Korostelev, A.A., Finer-Moore, J., Zhang, C., Shokat, K.M., Stroud, R.M., and Walter, P. 2009. The unfolded protein response signals through high-order assembly of Ire1. Nature, 457: 687-693.

Korennykh, A.V., Egea, P.F., Korostelev, A.A., Finer-Moore, J., Stroud, R.M., Zhang, C., Shokat, K.M., and Walter, P. 2011. Cofactor-mediated conformational control in the bifunctional kinase/RNase Ire1. $B M C$ Biol., 9: 48 .

Kozutsumi, Y., Segal, M., Normington, K., Gething, M.J., and Sambrook, J. 1988. The presence of malfolded proteins in the endoplasmic reticulum signals the induction of glucose-regulated proteins. Nature, 332: 462-464. 
Le, G.Q., Ishiwata-Kimata, Y., Huong, P.T, Fukunaka, S., Kohno, K., and Kimata, Y. 2021. The ADP-binding kinase region of Ire1 directly contributes to its responsiveness to endoplasmic reticulum stress. Sci. Rep., 11: 4506 .

Lee, K.P.K., Dey, M., Neculai, D., Cao, C., Dever, T.E., and Sicheri, F. 2008. Structure of the dual enzyme Ire1 reveals the basis for catalysis and regulation in nonconventional RNA splicing. Cell, 132: 89-100.

Li, H., Korennykh, A.V., Behrman, S.L., and Walter, P. 2010. Mammalian endoplasmic reticulum stress sensor IRE1 signals by dynamic clustering. Proc. Natl. Acad. Sci. USA, 107: 16113-16118.

Liu, C.Y., Schroder, M., and Kaufman, R.J. 2000. Ligand-independent dimerization activates the stress response kinases IRE1 and PERK in the lumen of the endoplasmic reticulum. J. Biol. Chem., 275: 2488124885 .

Ma, K., Vattem, K.M., and Wek, R.C. 2002. Dimerization and release of molecular chaperone inhibition facilitate activation of eukaryotic initiation factor-2 kinase in response to endoplasmic reticulum stress. J. Biol. Chem., 277: 18728-18735.

Mathuranyanon, R., Tsukamoto, T., Takeuchi, A., Ishiwata-Kimata, Y., Tsuchiya, Y., Kohno, K., and Kimata, Y. 2015. Tight regulation of the unfolded protein sensor Ire1 by its intramolecularly antagonizing subdomain. J. Cell Sci., 128: 1762-1772.

Maurel, M., Chevet, E., Tavernier, J., and Gerlo, S. 2014. Getting RIDD of RNA: IRE1 in cell fate regulation. Trends Biochem. Sci., 39: 245254

Merksamer, P.I., Trusina, A., and Papa, F.R. 2008. Real-time redox measurements during endoplasmic reticulum stress reveal interlinked protein folding functions. Cell, 135: 933-947.

Micoogullari, Y., Basu, S.S., Ang, J., Weisshaar, N., Schmitt, N.D., Abdelmoula, W.M., Lopez, B., Agar, J.N., Agar, N., and Hanna, J. 2020. Dysregulation of very-long-chain fatty acid metabolism causes membrane saturation and induction of the unfolded protein response. Mol. Biol. Cell, 31: 7-17.

Mitra, S. and Ryoo, H.D. 2019. The unfolded protein response in metazoan development. J. Cell Sci., 132: jcs217216.

Miyagawa, K., Ishiwata-Kimata, Y., Kohno, K., and Kimata, Y. 2014. Ethanol stress impairs protein folding in the endoplasmic reticulum and activates Ire1 in Saccharomyces cerevisiae. Biosci. Biotechnol. Biochem., 78: 1389-1391.

Mori, K., Ma, W., Gething, M.J., and Sambrook, J. 1993. A transmembrane protein with a cdc2+/CDC28-related kinase activity is required for signaling from the ER to the nucleus. Cell, 74: 743-756.

Nadanaka, S., Yoshida, H., and Mori, K. 2006. Reduction of disulfide bridges in the lumenal domain of ATF6 in response to glucose starvation. Cell Struct. Funct., 31: 127-134.

Nadanaka, S., Okada, T., Yoshida, H., and Mori, K. 2007. Role of disulfide bridges formed in the luminal domain of ATF6 in sensing endoplasmic reticulum stress. Mol. Cell. Biol., 27: 1027-1043.

Navarro-Tapia, E., Querol, A., and Pérez-Torrado, R. 2018. Membrane fluidification by ethanol stress activates unfolded protein response in yeasts. Microb. Biotechnol., 11: 465-475.

Nishitoh, H., Matsuzawa, A., Tobiume, K., Saegusa, K., Takeda, K., Inoue, K., Hori, S., Kakizuka, A., and Ichijo, H. 2002. ASK1 is essential for endoplasmic reticulum stress-induced neuronal cell death triggered by expanded polyglutamine repeats. Genes Dev., 16: 1345-1355.

Oikawa, D., Kimata, Y., Takeuchi, M., and Kohno, K. 2005. An essential dimer-forming subregion of the endoplasmic reticulum stress sensor Ire1. Biochem. J., 391: 135-142.

Oikawa, D., Kimata, Y., and Kohno, K. 2007. Self-association and BiP dissociation are not sufficient for activation of the ER stress sensor Ire1. J. Cell Sci., 120: 1681-1688,

Oikawa, D., Kimata, Y., Kohno, K., and Iwawaki, T. 2009. Activation of mammalian IRE1alpha upon ER stress depends on dissociation of BiP rather than on direct interaction with unfolded proteins. Exp. Cell Res., 315: 2496-2504.

Oka, O.B., van Lith, M., Rudolf, J., Tungkum, W., Pringle, M.A., and Bulleid, N.J. 2019. ERp18 regulates activation of ATF6 $\alpha$ during unfolded protein response. EMBO J., 38: e100990.

Okamura, K., Kimata, Y., Higashio, H., Tsuru, A., and Kohno, K. 2000. Dissociation of Kar2p/BiP from an ER sensory molecule, Ire1p, triggers the unfolded protein response in yeast. Biochem. Biophys. Res. Commun., 279: 445-450.

Papa, F.R., Zhang, C., Shokat, K., and Walter, P. 2003. Bypassing a kinase activity with an ATP-competitive drug. Science, 302: 1533-1537.

Pincus, D., Chevalier, M.W., Aragón, T., van Anken, E., Vidal, S.E., ElSamad, H., and Walter, P. 2010. BiP binding to the ER-stress sensor Ire1 tunes the homeostatic behavior of the unfolded protein response. PLoS Biol., 8: e1000415.

Pineau, L. and Ferreira, T. 2010. Lipid-induced ER stress in yeast and beta cells: parallel trails to a common fate. FEMS Yeast Res., 10: 10351045 .

Promlek, T., Ishiwata-Kimata, Y., Shido, M., Sakuramoto, M., Kohno, K., and Kimata, Y. 2011. Membrane aberrancy and unfolded proteins activate the endoplasmic reticulum stress sensor Ire1 in different ways. Mol. Biol. Cell, 22: 3520-3532.

Reinhard, J., Mattes, C., Väth, K., Radanović, T., Surma, M.A., Klose, C., and Ernst, R. 2020. A Quantitative analysis of cellular lipid compositions during acute proteotoxic ER stress reveals specificity in the production of asymmetric lipids. Front. Cell Dev. Biol., 8: 756.

Ricci, D., Marrocco, I., Blumenthal, D., Dibos, M., Eletto, D., Vargas, J., Boyle, S., Iwamoto, Y., Chomistek, S., Paton, J.C., Paton, A.W., and Argon, Y. 2019. Clustering of IRE1alpha depends on sensing ER stress but not on its RNase activity. FASEB J., 33: 9811-9827.

Rozpedek, W., Pytel, D., Mucha, B., Leszczynska, H., Diehl, J.A., and Majsterek, I. 2016. The role of the PERK/eIF2alpha/ATF4/CHOP signaling pathway in tumor progression during endoplasmic reticulum stress. Curr. Mol. Med., 16: 533-544.

Rubio, C., Pincus, D., Korennykh, A., Schuck, S., El-Samad, H., and Walter, P. 2011. Homeostatic adaptation to endoplasmic reticulum stress depends on Ire1 kinase activity. J. Cell Biol., 193: 171-184.

Sano, R. and Reed, J.C. 2013. ER stress-induced cell death mechanisms. Biochim. Biophys. Acta, 1833: 3460-3470.

Sato, Y., Nadanaka, S., Okada, T., Okawa, K., and Mori, K. 2011. Luminal domain of ATF6 alone is sufficient for sensing endoplasmic reticulum stress and subsequent transport to the Golgi apparatus. Cell Struct. Funct., 36: 35-47.

Schindler, A.J. and Schekman, R. 2009. In vitro reconstitution of ERstress induced ATF6 transport in COPII vesicles. Proc. Natl. Acad. Sci. USA, 106: 17775-17780.

Sepulveda, D., Rojas-Rivera, D., Rodríguez, D.A., Groenendyk, J., Köhler, A., Lebeaupin, C., Ito, S., Urra, H., Carreras-Sureda, A., Hazari, Y., Vasseur-Cognet, M., Ali, M.M.U., Chevet, E., Campos, G., Godoy, P., Vaisar, T., Bailly-Maitre, B., Nagata, K., Michalak, M., Sierralta, J., and Hetz, C. 2018. Interactome screening identifies the ER luminal chaperone Hsp47 as a regulator of the unfolded protein response transducer IRE1 $\alpha$. Mol. Cell, 69: 238-252.

Shamu, C.E. and Walter, P. 1996. Oligomerization and phosphorylation of the Ire1p kinase during intracellular signaling from the endoplasmic reticulum to the nucleus. EMBO J., 15: 3028-3039.

Shen, J., Chen, X., Hendershot, L., and Prywes, R. 2002. ER stress regulation of ATF6 localization by dissociation of BiP/GRP78 binding and unmasking of Golgi localization signals. Dev. Cell, 3: 99-111.

Shen, J., Snapp, E.L., Lippincott-Schwartz, J., and Prywes, R. 2005. Stable binding of ATF6 to $\mathrm{BiP}$ in the endoplasmic reticulum stress response. Mol. Cell. Biol., 25: 921-932.

Shoulders, M.D., Ryno, L.M., Genereux, J.C., Moresco, J.J., Tu, P.G., Wu, 
C., Yates, J.R., Su, A.I., Kelly, J.W., and Wiseman, R.L. 2013. Stressindependent activation of XBP1s and/or ATF6 reveals three functionally diverse ER proteostasis environments. Cell Rep., 3: 1279-1292.

Shyu, P., Jr., Ng, B.S.H., Ho, N., Chaw, R., Seah, Y.L., Marvalim, C., and Thibault, G. 2019. Membrane phospholipid alteration causes chronic ER stress through early degradation of homeostatic ER-resident proteins. Sci. Rep., 9: 8637.

Sidrauski, C. and Walter, P. 1997. The transmembrane kinase Irelp is a site-specific endonuclease that initiates mRNA splicing in the unfolded protein response. Cell, 90: 1031-1039.

Sundaram, A., Appathurai, S., Plumb, R., and Mariappan, M. 2018. Dynamic changes in complexes of IRE1 $\alpha$, PERK, and ATF6 $\alpha$ during endoplasmic reticulum stress. Mol. Biol. Cell, 29: 1376-1388.

Tam, A.B., Roberts, L.S., Chandra, V., Rivera, I.G., Nomura, D.K., Forbes, D.J., and Niwa, M. 2018. The UPR Activator ATF6 responds to proteotoxic and lipotoxic stress by distinct mechanisms. Dev. Cell, 46: 327-343.e7.

Thibault, G., Shui, G., Kim, W., McAlister, G.C., Ismail, N., Gygi, S.P., Wenk, M.R., and Ng, D.T. 2012. The membrane stress response buffers lethal effects of lipid disequilibrium by reprogramming the protein homeostasis network. Mol. Cell, 48: 16-27.

Thuerauf, D.J., Morrison, L., and Glembotski, C.C. 2004. Opposing roles for ATF6alpha and ATF6beta in endoplasmic reticulum stress response gene induction. J. Biol. Chem., 279: 21078-21084.

Todd-Corlett, A., Jones, E., Seghers, C., and Gething, M.-J. 2007. Lobe IB of the ATPase domain of Kar2p/BiP interacts with Irelp to negatively regulate the unfolded protein response in Saccharomyces cerevisiae. J. Mol. Biol., 367: 770-787.

Tran, D.M., Takagi, H., and Kimata, Y. 2019. Categorization of endoplasmic reticulum stress as accumulation of unfolded proteins or membrane lipid aberrancy using yeast Ire1 mutants. Biosci. Biotechnol. Biochem., 83: 326-329.

Travers, K.J., Patil, C.K., Wodicka, L., Lockhart, D.J., Weissman, J.S., and Walter, P. 2000. Functional and genomic analyses reveal an essential coordination between the unfolded protein response and ER-associated degradation. Cell, 101: 249-258.

Tsuru, A., Fujimoto, N., Takahashi, S., Saito, M., Nakamura, D., Iwano, M., Iwawaki, T., Kadokura, H., Ron, D., and Kohno, K. 2013. Negative feedback by IRE1 $\beta$ optimizes mucin production in goblet cells. Proc. Natl. Acad. Sci. USA, 110: 2864-2869.

Upton, J.-P., Wang, L., Han, D., Wang, E.S., Huskey, N.E., Lim, L., Truitt, M., McManus, M.T., Ruggero, D., Goga, A., Papa, F.R., and Oakes, S.A. 2012. IRE1 $\alpha$ cleaves select microRNAs during ER stress to derepress translation of proapoptotic Caspase-2. Science, 338: 818-822.

Urano, F., Wang, X., Bertolotti, A., Zhang, Y., Chung, P., Harding, H.P., and Ron, D. 2000. Coupling of stress in the ER to activation of JNK protein kinases by transmembrane protein kinase IRE1. Science, 287: 664-666.

van Anken, E., Pincus, D., Coyle, S., Aragon, T., Osman, C., Lari, F., Gomez Puerta, S., Korennykh, A.V., and Walter, P. 2014. Specificity in endoplasmic reticulum-stress signaling in yeast entails a step-wise engagement of HAC1 mRNA to clusters of the stress sensor Ire1. eLife, 3: $\mathrm{e} 05031$.

Venditti, R., Wilson, C., and De Matteis, M.A. 2014. Exiting the ER: what we know and what we don't. Trends Cell Biol., 24: 9-18.

Volmer, R., van der Ploeg, K., and Ron, D. 2013. Membrane lipid saturation activates endoplasmic reticulum unfolded protein response transducers through their transmembrane domains. Proc. Natl. Acad. Sci. USA, 110: 4628-4633.

Wang, P., Li, J., and Sha, B. 2016. The ER stress sensor PERK luminal domain functions as a molecular chaperone to interact with misfolded proteins. Acta Crystallogr. D Struct. Biol., 72: 1290-1297.

Wiseman, R.L., Zhang, Y., Lee, K.P., Harding, H.P., Haynes, C.M., Price, J., Sicheri, F., and Ron, D. 2010. Flavonol activation defines an unanticipated ligand-binding site in the kinase-RNase domain of IRE1. Mol. Cell, 38: 291-304.

Yamamoto, K., Sato, T., Matsui, T., Sato, M., Okada, T., Yoshida, H., Harada, A., and Mori, K. 2007. Transcriptional induction of mammalian ER quality control proteins is mediated by single or combined action of ATF6alpha and XBP1. Dev. Cell, 13: 365-376.

Yang, F. and Luo, J. 2015. Endoplasmic reticulum stress and ethanol neurotoxicity. Biomolecules, 5: 2538-2553.

Ye, J., Rawson, R.B., Komuro, R., Chen, X., Davé, U.P., Prywes, R., Brown, M.S., and Goldstein, J.L. 2000. ER stress induces cleavage of membrane-bound ATF6 by the same proteases that process SREBPs. Mol. Cell, 6: 1355-1364.

Yoshida, H., Okada, T., Haze, K., Yanagi, H., Yura, T., Negishi., M., and Mori, K. 2000. ATF6 activated by proteolysis binds in the presence of NF-Y (CBF) directly to the cis-acting element responsible for the mammalian unfolded protein response. Mol. Cell. Biol., 20: 6755-6767.

Yoshida, H., Matsui, T., Yamamoto, A., Okada, T., and Mori, K. 2001. XBP1 mRNA is induced by ATF6 and spliced by IRE1 in response to ER stress to produce a highly active transcription factor. Cell, 107: 881891.

Yoshida, H., Matsui, T., Hosokawa, N., Kaufman, R.J., Nagata, K., and Mori, K. 2003. A time-dependent phase shift in the mammalian unfolded protein response. Dev. Cell, 4: 265-271.

Zhou, J., Liu, C.Y., Back, S.H., Clark, R.L., Peisach, D., Xu, Z., and Kaufman, R.J. 2006. The crystal structure of human IRE1 luminal domain reveals a conserved dimerization interface required for activation of the unfolded protein response. Proc. Natl. Acad. Sci. USA, 103: 14343-14348.

Zinszner, H., Kuroda, M., Wang, X., Batchvarova, N., Lightfoot, R.T., Remotti, H., Stevens, J.L., and Ron, D. 1998. CHOP is implicated in programmed cell death in response to impaired function of the endoplasmic reticulum. Genes Dev., 12: 982-995.

(Received for publication, February 6, 2021, accepted, March 11, 2021 and published online, March 26, 2021) 